\title{
非定常船体運動のリアルタイム高次スペクトル解析
}

\author{
井関 俊夫*・増山 聡**
}

\section{Real-Time Higher Order Spectral Analysis of Non-stationary Ship Motion Data}

\author{
Toshio ISEKI and Satoshi MASHIYAMA
}

\begin{abstract}
A real-time algorithm of higher order spectral analysis is proposed in order to investigate the non-linear and non-stationary ship motions. The algorithm is based on the time-varying vector auto-regressive (TVVAR) modeling and can be considered as an extension of the instantaneous power spectral analysis. The TVVAR model is fitted to the data using the Kalman filter algorithm and the instantaneous higher order spectra can be evaluated by using the TVVAR coefficients. In order to examine the validity of the proposed algorithm, numerical simulations of the real-time estimation of instantaneous higher order spectra was carried out based on the full scale ship motion data. The accuracy of the proposed algorithm was investigated by comparing with the stationary analysis based on the FFT. Furthermore, the algorithm was extended to the trispectral analysis and a result was shown to demonstrate the usefulness of the proposed algorithm.
\end{abstract}

Keywords : Information processing, Higher order spectrum, TVVAR modeling, Non-linear ship motions. キーワード: 情報処理, 高次スペクトル，TVVAR モデル，非定常船体運動

\section{1. 緒言}

近年、荒天中の大振幅動摇やパラメトリックロー リングのような非線形船体応答が注目されている ${ }^{(1)}$ 。 これらの非線形現象の解析に対しては、線形理論に 基づいた従来のスペクトル解析、すなわちパワース ペクトルを用いた確率統計的手法は、周波数領域に おけるエネルギー漏洩等が起こるため適切ではなく、 高次スペクトル(2)を用いた解析法を導入する必要が あると指摘されている(3)、(4)。しかしながら、船体動 摇の非線形性については、従来、横摇れ減衰力の非 線形性のみが注目され、通常の船体動摇に対してこ れらの高次スペクトル解析法が適用された例 ${ }^{(5),(6)}$ は 非常に少なく、一般的知見が少ないのが現状である。

著者の一人は以前、一変数の時変倸数自己回帰モ デルに基づく瞬間バイスペクトル解析法を提案し、 実船実験で得られた追い波中縦摇れ時系列のデータ を解析した (7)。その結果、時間的に変動するバイス ペクトルが解析可能であることを示すとともに、瞬
間バイスペクトルの複素平面におけるピーク位置と 時系列に現れる歪度の変動は密接に関係しているこ とを明らかにした。さらに、パラメトリックローリ ング等の非線形現象は多変量の時系列を処理する必 要があると考えられるため、時変係数多変量自己回 帰モデル（以下、TVVAR モデル）を用いたリアル タイムの高次スペクトル解析手法を開発した ${ }^{(8)}$ 。こ の方法では、カルマンフィルタによるオフラインで の解の平滑化を行うことができず、MAICE 法による 最適次数の決定を行うことができない等の改善を要 する部分はあるものの、船体動摇高次スペクトルの 変動をリアルタイムでモニタリングすることにより、 パラメトリックローリング等の非線形船体応答を予 知できる可能性があると考えられる。

本報告では、実船実験で収集した船体動摇データ に対して多変量の瞬間高次スペクトル解析手法を適 用し、周波数平面における特徵とその非定常性につ いて検討を行った結果について述べる。
* 正 会 員 東京海洋大学海洋工学部 （T135-8533 ** 学生会員 東京海洋大学大学院海洋科学技術研究科
東京都江東区越中島 2-1-6） iseki@kaiyodai.ac.jp （广135-8533 東京都江東区越中島 2-1-6） 


\section{TVVAR モデルの概要}

TVVAR モデルによる瞬間スペクトル解析法につ いては以前の論文 ${ }^{(9)} に$ 詳述されているので、ここで は概要のみを述べる。

$$
\mathbf{y}(n)=\left\{y_{1}(n), y_{2}(n), \cdots, y_{p}(n)\right\},(n=1, \cdots, N) \text { で表 }
$$
される $p$ 変量多次元時系列の解析に用いられる TVVAR モデルは次のように定義される。

$$
\mathbf{y}(n)=\sum_{l=1}^{m} \mathbf{A}_{l}(n) \mathbf{y}(n-l)+\mathbf{w}(n)
$$

ここで、 $\mathbf{A}_{l}(n)$ は時刻 $n$ において定義されるラグ $l$ の $p \times p$ の自己回帰係数行列であり、 $\mathbf{w}(n)$ は平均值 0 、分散共分散行列 $\Sigma(n)$ の $p$ 変量正規分布に従う白 色雑音を表す。このモデルの未知数は $p \times p \times m \times N$ 個の膨大な量の時変 AR 係数であり、時々刻々のモ デルの当てはめにおいては膨大な演算量と記憶容量 が必要となるので、同時刻の応答を含む TVVAR モ デルを導入し計算の効率化を図る。

$$
\mathbf{y}(n)=\mathbf{D}(n) \mathbf{y}(n)+\sum_{l=1}^{m} \mathbf{B}_{l}(n) \mathbf{y}(n-l)+\mathbf{u}(n)
$$

ここで、 $\mathbf{D}(n)$ と $\mathbf{B}_{l}(n)$ はそれぞれ時刻 $n$ での同時応 答行列と保数行列である。また、 $\mathbf{u}(n)$ は平均値 0 、 分散共分散行列 $\mathbf{V}$ の $p$ 変量正規分布に従う白色雑 音であり、

$$
\begin{aligned}
& \mathbf{u}(n)=\left\{u_{1}(n), u_{2}(n), \cdots, u_{p}(n)\right\}^{T} \\
& \mathbf{V}=\operatorname{diag}\left(\sigma_{1}^{2}, \sigma_{2}^{2}, \cdots, \sigma_{p}^{k}\right)
\end{aligned}
$$

で表される。(1)式と(2)式における TVVAR 倸数行列 および分散共分散行列の間には、

$$
\begin{aligned}
& \mathbf{A}_{l}(n)=(\mathbf{I}-\mathbf{D}(n))^{-1} \mathbf{B}_{l}(n),(l=1,2, \cdots, p), \\
& \Sigma(n)=(\mathbf{I}-\mathbf{D}(n))^{-1} \mathbf{V}(\mathbf{I}-\mathbf{D}(n))^{-T}
\end{aligned}
$$

の関係があるので、一旦どちらかのモデルの推定が できればもう一方のモデルも自然に得られることに なる。

さらに、 $u_{i}(n)$ と $u_{j}(n),(i \neq j)$ が互いに独立であ ると仮定すると、(3)式で表されるモデルは $b_{i j 0}(n)=0,(i \leq j)$ とすれば、

$$
\begin{gathered}
y_{i}(n)=\sum_{j=1}^{p} \sum_{l=0}^{m} b_{i j l}(n) y_{j}(n-l)+u_{i}(n), \\
(i=1,2, \cdots, p)
\end{gathered}
$$

のように $p$ 個の独立したモデルに分解することが 可能となり、計算効率の飛躍的な向上させることが できる。
次に、 $b_{i j l}(n)$ を効率的に求めるために、パラメー タの時間変化に対してベイズ型平滑化事前分布を適 用し、モデルの推定を安定的に行う。ベイズ型平滑 化事前分布は $b_{i j l}(n)$ が滑らかに変化するという仮定 を設けるもので、

$$
\begin{aligned}
& \Delta^{k} b_{i j l}(n)=v_{i j l}(n), \\
& \quad(i, j=1,2, \cdots, p, l=1,2, \cdots, m)
\end{aligned}
$$

で表される確率差分方程式を考慮することによって モデルに導入することができる。ここで、、は差分 オペレータを表し、

$$
\begin{aligned}
& \Delta b_{i j l}(n)=b_{i j l}(n)-b_{i j l}(n-1), \\
& \Delta^{k} b_{i j l}(n)=\Delta^{k-1}\left(\Delta b_{i j l}(n)\right)
\end{aligned}
$$

の演算を意味し、 $v_{i j l}(n)$ は平均値 0 、未知分散 $\tau_{i j l}^{2}$ の 正規白色雑音を表す。

したがって、未知分散 $\tau_{i j l}^{2}$ はモデルの適合度と係数 の滑らかさのトレードオフをコントロールするハイ パー・パラメータと考えることができる。

実際の解法は、(6)式をシステムモデル、(5)式を観 測モデルとした次のような状態空間表現を用いて行 われる。

$$
\begin{aligned}
\mathbf{x}(n) & =\mathbf{F} \mathbf{x}(n-1)+\mathbf{G v}(n) \\
y_{i}(n) & =\mathbf{H}(n) \mathbf{x}(n)+w_{i}(n), \quad(i=1,2, \cdots, p)
\end{aligned}
$$

ここで、

$$
\begin{aligned}
\mathbf{x}(n)= & \left(b_{i 10}(n), \cdots, b_{l(i-1) 0}(n), b_{i 11}(n), \cdots,\right. \\
& \left.b_{i 1 m}(n), \cdots, b_{i p 1}(n), \cdots, b_{i p m}(n)\right)^{T} \\
\mathbf{H}(n)= & \left(y_{1}(n), \cdots, y_{i-1}(n), y_{1}(n-1), \cdots,\right. \\
& \left.y_{1}(n-m), \cdots, y_{p}(n-1), \cdots, y_{p}(n-m)\right)^{T}
\end{aligned}
$$

であり、 $k=1$ のときは $\mathbf{I}_{L}$ を $L \times L$ の単位行列として、

$$
\mathbf{F}=\mathbf{G}=\mathbf{I}_{L}
$$

$k=2$ のときは

$$
\mathbf{F}=\left(\begin{array}{cc}
2 \mathbf{I}_{L} & -\mathbf{I}_{L} \\
\mathbf{I}_{L} & \mathbf{0}
\end{array}\right), \mathbf{G}=\left(\begin{array}{c}
\mathbf{I}_{L} \\
\mathbf{0}
\end{array}\right)
$$

で表される。ただし、 $L$ は $L=m \times p+i-1$ で決定さ れる整数である。

このように状態空間モデルが構成されれば、カル マンフィルタのアルゴリズムを用いて TVVAR 係数 を時々刻々推定することができる。すなわち、非定 常な時系列 $y_{i}(n),(i=1, \cdots, p)$ と初期条件 $\mathbf{x}(0 \mid 0)$ お よび $\mathbf{V}(0 \mid 0)$ が与えられると、具体的なカルマンフ 
イルタのアルゴリズムは以下に示す 1 期先予測とフ イルタリングの繰り返しによって与えられる。

(1 期先予測)

$$
\begin{aligned}
\mathbf{x}(n \mid n-1) & =\mathbf{F x}(n-1 \mid n-1), \\
\mathbf{V}(n \mid n-1) & =\mathbf{F V}(n-1 \mid n-1) \mathbf{F}^{T}+\tau_{i}^{2} \mathbf{G G}^{T}
\end{aligned}
$$

(フィルタリング)

$$
\begin{aligned}
\mathbf{K}(n)= & \mathbf{V}(n \mid n-1) \mathbf{H}^{T}(n) \\
\times & \left\{\mathbf{H}(n) \mathbf{V}(n \mid n-1) \mathbf{H}^{T}(n)+\sigma_{i}^{2}\right\}^{-1} \\
\mathbf{x}(n \mid n) & =\mathbf{x}(n \mid n-1)+\mathbf{K}(n) \\
& \times\left\{y_{i}(n)-\mathbf{H}(n) \mathbf{x}(n \mid n-1)\right\} \\
\mathbf{V}(n \mid n) & =\{\mathbf{I}-\mathbf{K}(n) \mathbf{H}(n)\} \mathbf{V}(n \mid n)
\end{aligned}
$$

なお、このモデルには推定すべきパラメータとし て観測ノイズの分散 $\sigma_{i}^{2}$ とシステムノイズの分散 $\tau_{i}^{2}$ が含まれているが、 $\sigma_{i}^{2}$ が一定であるとみなせる場 合には、トレードオフパラメータ $\lambda_{i}^{2}\left(=\tau_{i}^{2} / \sigma_{i}^{2}\right)$ を導 入し、次式で表される対数尤度関数 $l\left(\lambda_{i}\right)$ を最大化す ることによって決定することができる。

$$
\begin{aligned}
l\left(\lambda_{i}\right) & =-\frac{1}{2}\left\{N \log 2 \pi+\sum_{n=1}^{N} \log v^{2}(n)\right. \\
& +\sum_{n=1}^{N} \frac{1}{v^{2}(n)}\left\{y_{i}(n)-\mathbf{H}(n) \mathbf{x}(n \mid n-1)\right\}^{2}
\end{aligned}
$$

ここで、 $v^{2}(n)$ は時刻 $n$ の予測誤差の分散を表し、

$$
v^{2}(n)=\mathbf{H}(n) \mathbf{V}(n \mid n-1) \mathbf{H}(n)^{T}+\sigma_{i}^{2}
$$

で求められる。また、 $\mathbf{x}(n \mid n-1), \mathrm{V}(n \mid n-1)$ はカル マンフィルタによって 1 期先を予測された時刻 $n-1$ の状態ベクトルと分散共分散行列を表す。

一方、本来の TVVAR モデルの解析では、モデル の次数 $\mathrm{m}$ と確率差分方程式の次数 $k$ としては、

$$
\begin{aligned}
& A I C(i)=-2 l\left(\lambda_{i}\right)+2\left(\text { dimension of } \lambda_{i}\right) \\
& A I C=\sum_{i=1}^{p} A I C(i)
\end{aligned}
$$

で定義される AICを最小にするものを選んで決定す ることができるが、本研究のようなリアルタイムの 解析では、途中での次数の変更ができないため、あ らかじめ適切な值を設定しておく必要がある。

\section{3. 瞬間高次クロススペクトルの推定}

TVVAR 係数行列を推定することができれば、(1) 式のフーリエ変換は次のように表される。

$$
\mathbf{Y}(f, n)=\mathbf{A}(f, n)^{-1} \mathbf{W}(f, n)
$$

ここで、

$$
\left\{\begin{array}{l}
\mathbf{A}(f, n)=\sum_{l=0}^{m} \mathbf{A}_{l}(n) e^{-2 \pi f l \Delta t}, \mathbf{A}_{0}(n)=-\mathbf{I} \\
\mathbf{Y}(f, n)=\sum_{l=0}^{m} \mathbf{y}(n) e^{-2 \pi f f \Delta}, \\
\mathbf{W}(f, n)=\sum_{l=0}^{m} \mathbf{w}(n) e^{-2 \pi f l \Delta t}
\end{array}\right.
$$

白色雑音のフーリエ変換 $\mathbf{W}(f, n)$ は(5)式で表さ れる対角共分散行列 $\mathbf{V}$ とし求められ、その要素は 予測誤差を用いて次式で与えられる。

$$
\sigma_{i}^{2}=\sum_{n=1}^{N} \frac{1}{v^{2}(n)}\left\{y_{i}(n)-\mathbf{H}(n) \mathbf{x}(n \mid n-1)\right\}^{2},
$$

ここで、 $\mathbf{W}(f, n)$ は白色雑音と定義されているので、 共分散は周波数に依存しない定数となる。

(17)式に示されるフーリエ変換を用いて、瞬間パ ワースペクトルと瞬間高次スペクトルは次のように 表される。

(瞬間パワースペクトル)

$\mathbf{P}_{\mathbf{Y Y}}(f, n)=\Delta t \mathbf{Y}(f, n) \mathbf{Y}(f, n)^{* T}$

(瞬間バイスペクトル)

$\mathbf{P}_{\mathbf{Y Y Y}}\left(f_{1}, f_{2}, n\right)=\Delta t^{2} \mathbf{Y}\left(f_{1}, n\right) \mathbf{Y}\left(f_{2}, n\right) \mathbf{Y}\left(f_{1}+f_{2}, n\right)^{* T}$

(瞬間トライスペクトル)

$$
\begin{aligned}
\mathbf{P}_{\mathbf{Y Y Y Y}}\left(f_{1}, f_{2}, f_{3}, n\right)= & \Delta t^{3} \mathbf{Y}\left(f_{1}, n\right) \mathbf{Y}\left(f_{2}, n\right) \\
& \mathbf{Y}\left(f_{3}, n\right) \mathbf{Y}\left(f_{1}+f_{2}+f_{3}, n\right)^{* T}
\end{aligned}
$$

ここで、*と ${ }^{T}$ は複素共役と遷移行列を表す。

\section{4. 実船実験データ}

リアルタイム瞬間バイスペクトル解析の対象とす る実船実験データとしては、過去の FFTに基づく定 常バイスペクトル解析結果 ${ }^{(6)}$ と比較するために、平 成 13 年 3 月 7 日、東京海洋大学附属練習船汐路丸 による実験航海のデータを使用した。実験時の海域 と航跡は Fig.1 に示すとおりである。船体動摇は光 ファイバージャイロを用いて計測し、時系列データ は 0.5 秒のサンプリング周期で収録した。計測項目 は、 3 軸方向の加速度、回転角、回転角速度、船首 波高、主機関の負荷指針ならびに内蔵 GPSによる船 位、針路、船速、UTC である。

Fig.2 は本研究で開発したリアルタイム高次スペ クトル解析プログラムの GUI を示しており、船位、 


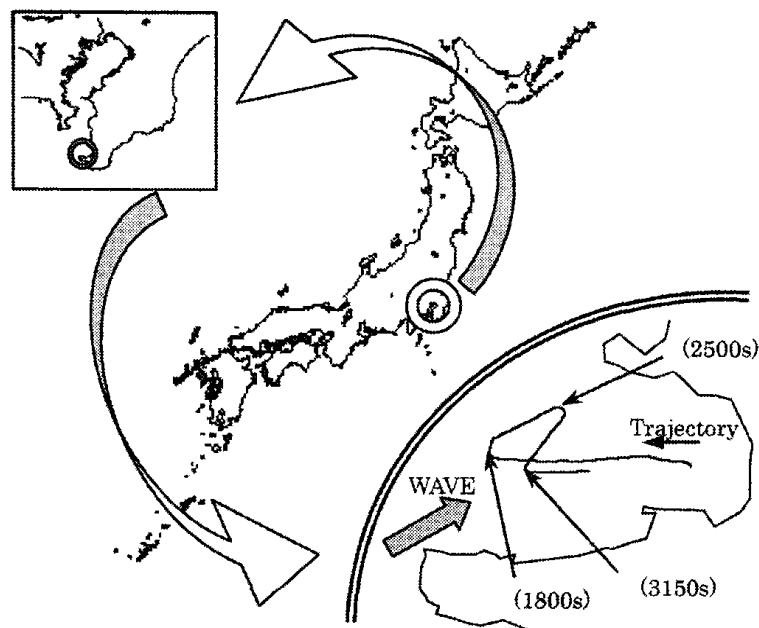

Fig.1 Experimental area and trajectory

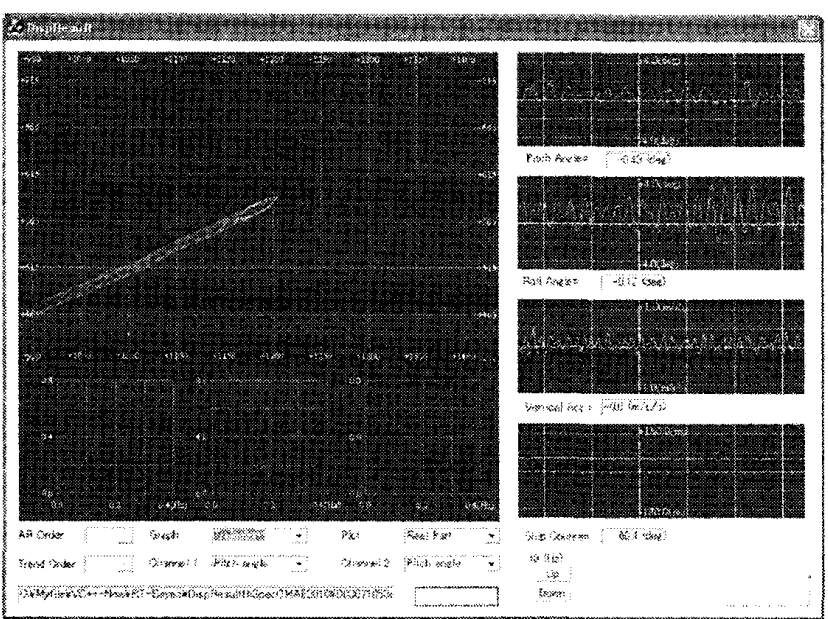

Fig.2 Screenshot of GUI of the proposed system
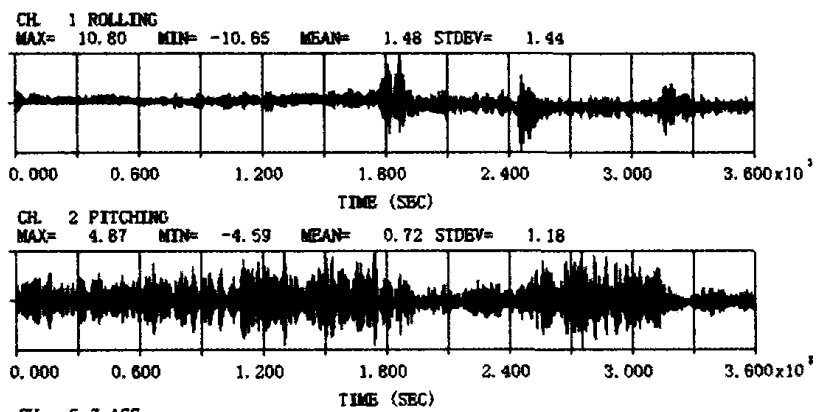

${ }_{M A X} 5$ 2-ACC. $3.05=-2.70 \quad-9.71$ STDEV $=0.72$

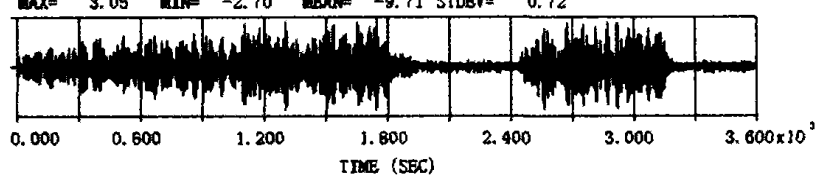

Fig.3 Measured time history data of roll angle, pitch angle and vertical acceleration.

船体運動時系列および各パワースペクトルが確認で きるだけではなく、TVVAR モデルのフィッティン グ状況も監視できるようになっている。なお、 TVVAR モデルに関する主要計算部分は FORTRAN、 GUI に関する部分は MS Visual C++で開発されてお

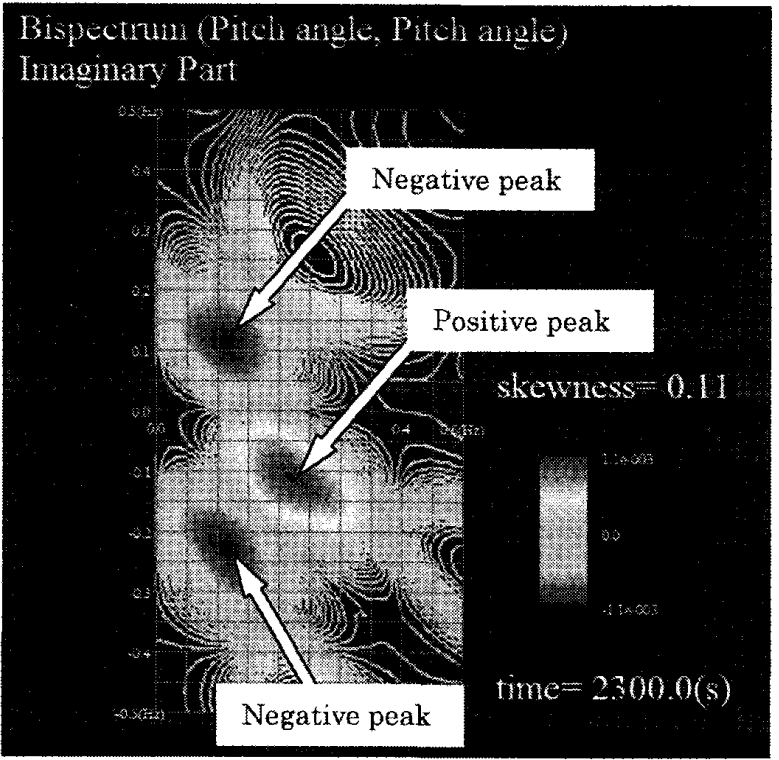

Fig.4 Pitching instantaneous bispectrum measured on a straight course.

り、通常のノートパソコンで実行可能である。また、 本報告での解析では、動摇データを計測する代わり に、上記実船実験で計測したデータファイルから読 み取ることでデータ計測をシミュレートしており、 データファイルは前述の各計測項目をサンプリング 周期ごとに記録したテキストファイルとなっている。

Fig.3に計測された時系列データの一部を示す。 図は上から横摇れ角、縦摇れ角、上下加速度を示し ており、1 時間の連続データを圧縮して示している。 なお、示されている時系列については、スペクトル 解析における直流成分や長周期成分の発生を抑える ために、あらかじめトレンドモデルによって定常風 による横傾斜、船速によるトリム変化、変針時の外 方傾斜等によるトレンドを除去している。

\section{5. 䁌間パスペクトル解析結果}

Fig. 4 は追い波中、直進時の縦摇れ瞬間バイスペ クトル解析結果を示している。図はバイスペクトル の虚数部を示しており、横軸に $f_{l}$ 、縦軸に $f_{2}$ をとっ ている。グラフの $f_{1}=0.12 \mathrm{~Hz}, f_{2}=0.12 \mathrm{~Hz}$ と $f_{l}=0.12 \mathrm{~Hz}$, $f_{2}=-0.22 \mathrm{~Hz}$ に負のピーク、 $f_{1}=0.22 \mathrm{~Hz}, f_{2}=-0.12 \mathrm{~Hz}$ に正 のピークが現れていることが分かる。 $0.12 \mathrm{~Hz}$ は本デ 一タの縦摇れのピーク周波数であり、0.22Hzはバイ

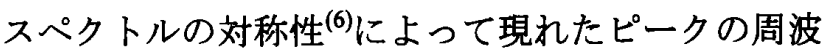
数と思われる。また、バイスペクトルを積分して得 られる歪度 (skewness) も 10,000 倍して示してある。 本データは直進中のデータであり、定常時系列とみ なすことができるので、FFT に基づく定常バイスペ クトル解析結果 ${ }^{(6)}$ と比較が可能である。比較の結果、 ピーク位置の一致は良好であり、FFTによる結果よ 


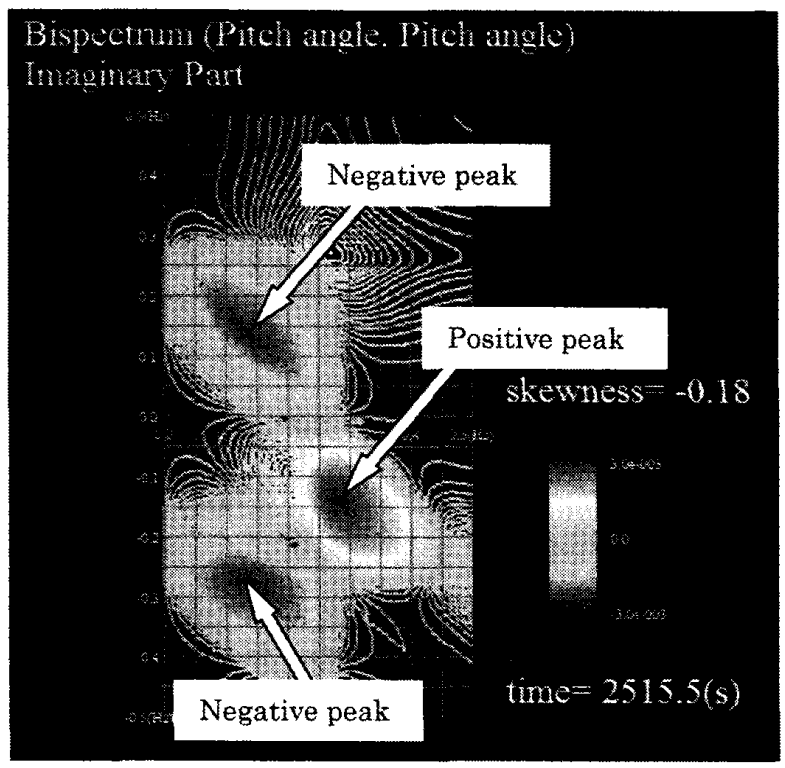

Fig.5 Pitching instantaneous bispectrum measured during course alteration.

Table 1 Comparisons of skewness evaluated from integrating the bispectra.

\begin{tabular}{|c|c|c|}
\cline { 2 - 3 } \multicolumn{1}{c|}{} & \multicolumn{2}{c|}{ Skewness $\times 10^{4}$} \\
\hline & Straight & Turning \\
\hline Pitching & 0.11 & -0.18 \\
\hline Rolling & -3.03 & -7.30 \\
\hline V. Acc. & -0.10 & 0.50 \\
\hline
\end{tabular}

りも滑らかなスペクトルが得られていることが確認 できた (8)。

Fig. 5 には、旋回中の綐摇れ瞬間バイスペクトル 解析結果を示している。時系列データでは 2515.5 秒 経過後であり、Fig. 3 のグラフでは横摇れデータが 一時的に大振幅となっている部分に相当する。追い 波状態から横波状態に変化している途中であるので、 綐摇周期が短くなり、バイスペクトルのピーク周波 数がわずかに高周波側にずれていることが分かる。 また、Fig. 4 の直進状態と比較すると歪度が高くな っていることが分かる。これらのことから、本計算 法によれば、旋回中の非定常時系列データに対して も安定して瞬間バイスペクトルが可能であるといえ る。

Table 1 には、綐摇れ、横摇れおよび上下加速度に ついて直進中と旋回中の歪度を比較したものを示し ている。歪度が最も大きいものは横摇れであるが、 全ての運動について、旋回中に歪度が増大している ことが分かる。一般に、動摇の対称性が崩れると歪 度が増加する傾向があるが、縦摇れと上下加速度は 波向き変化による復原力変動 ${ }^{(7)}$ の影響、横摇れは外

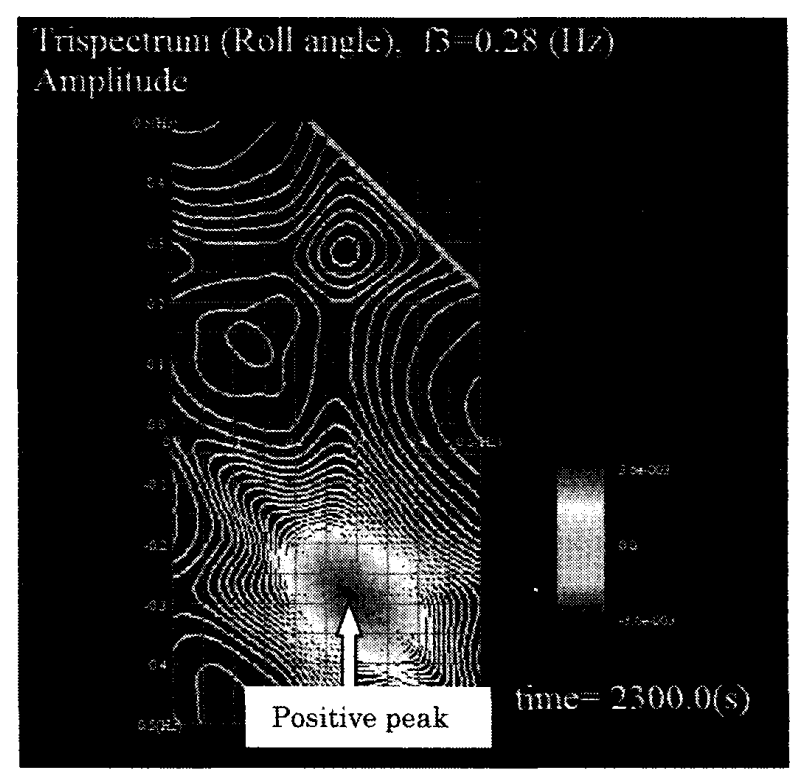

Fig.6 Amplitude of the instantaneous trispectrum of rolling motion.

Table 2 Peak frequencies of the instantaneous trispectrum of rolling motion.

\begin{tabular}{|c|c|c|c|}
\hline & $\mathrm{f}_{1}$ & $\mathrm{f}_{2}$ & $\mathrm{f}_{3}$ \\
\hline Pitching & 0.16 & -0.16 & 0.16 \\
\hline Rolling & 0.28 & -0.28 & 0.28 \\
\hline
\end{tabular}

方傾斜による左右復原力の非対称性の影響により歪 度が変化したものと考えられる。

\section{6. 䁌间トライスペクトル解析結果}

Fig. 6 は追い波中の横摇れ瞬間トライスペクトル の一例を示している。（21)式に示すように、トライ スペクトルは 3 つの周波数で定義されるのでグラフ 化することが困難である。したがって、Fig. 6 では $f_{3}=0.28(\mathrm{~Hz})$ におけるトライスペクトルの断面を等 高線表示している。この断面を見ると $f_{1}=0.28(\mathrm{~Hz}) 、$ $f_{2}=-0.28(\mathrm{~Hz})$ にピークがあることが分かる。周波 数 $f_{3}$ を種々変化させてピーク値を調べたところ、収 録時の横摇れ周波数と等しい $f_{3}=0.28(\mathrm{~Hz})$ における トライスペクトルの值が最も高いことが分かった。

Table 2 には、追い波中の縦摇れと横摇れについ て瞬間トライスペクトルが最大值をとる周波数を調 ベた結果を示している。綐摇れ瞬間トライスペクト ルのピークは計測時の綐摇れ周波数と等しい $f_{1}=0.16(\mathrm{~Hz}), f_{2}=-0.16(\mathrm{~Hz}), f_{3}=0.16(\mathrm{~Hz})$ であっ た。この解析で用いたデータではパラメトリックロ ーリングは実際に発生していないので、縦摇れと横 摇れの組み合わせ周波数位置、例えば $f_{1}=0.16(\mathrm{~Hz})$, 
$f_{2}=-0.28(\mathrm{~Hz}), f_{3}=0.16(\mathrm{~Hz})$ 等では、トライスペク トルのピークを見つけることはできなかった。今後、 コンピュータ・シミュレーションや模型実験によっ てパラメトリックローリングのデータを発生させ、

瞬間高次スペクトルの物理的意味に関する知見を得 る必要がある。その場合、本報告で提案した手法を 用いれば、リアルタイムで瞬間トライスペクトルを 求めることができるので、効率的に研究を進めるこ とが可能であると思われる。

\section{7. 結言}

本報では、実船実験で収集した船体動摇データに 対して多変量の瞬間高次スペクトル解析手法を適用 し、周波数平面における特徴とその非定常性につい て検討を行った。得られた結果をまとめると以下の ようになる。

・ TVVAR モデルの当てはめと瞬間高次スペクト ルの推定は実際のデータサンプリング周期内で 実行可能であることを確認した。

・瞬間バイスペクトルの解析結果より。縦摇れ、 横摇れ、上下加速度の歪度は旋回中に大きくな る傾向が見られた。

・瞬間トライスペクトルの推定にも本アルゴリズ ムは適用可能であることを確認した。

・ 今後、トライスペクトルの物理的意味の理解を 含め、本解析法を用いて、さらなる研究が必要 である。

以上より、本アルゴリズムは非線形・非定常時系 列の高次スペクトル解析に対して便利で有効な環境 を実現できると思われる。

\section{謝辞}

本研究成果の一部は文部科学省科学研究費補助金 （基盤研究(C) 課題番号 20560744）の援助によるこ とを付記し、関係各位に深く感謝いたします。

\section{参考文献}

(1) 梅田直哉:実海域の復原性能, 日本造船学会誌, TECHNO MARINE，第 884 号,pp.61-66,2005.

(2) D. R. Brillinger and M. Rosenblatt: Asymptotic Theory of Estimates of k-th Order Spectra, in Advanced Seminar on Spectral Analysis of Time Series, B. Harris, ed., pp.153-188, Wiley, 1967.

（3）山内保文,大津皓平:船の応答の非線型性と高次 元スペクトラムーバイスペクトラムの応用一, 日本造船学会論文集,第 131 号, pp.115-135, 1972.
（4）細田龍介:高次スペクトル解析の応用,運動性能 委員会第 1 回シンポジウム, pp.145-151, 1984.

(5) J. F. Dalzell, Cross-Bispectral Analysis - Application to Ship Resistance in Waves, J. Ship Research, Vol.18, No.1, pp.62-72, 1974.

(6) 井関俊夫, 非線形船体応答のバイスペクトル解 析, 日本航海学会論文集, 第 116 号, pp.161-166, 2007.3.

（7）井関俊夫, 非線形船体応答のバイスペクトル解 析-II.- 非線形復原力変動の影響 - , 日本航 海学会論文集, 第 118 号, pp.177-183，2008.3.

(8) Iseki, T., Real-Time Analysis of Higher Order Ship Motion Spectrum, Proc. OMAE2010, 20521, p.1-7, 2010.6.

（9）井関俊夫, 非定常船体動摇データの時系列解析 についてーII.- 多変量時系列データの瞬間ク ロススペクトル解析 一, 日本航海学会論文集, 第 114 号, pp.151-156，2006.3.

\section{質疑応答}

寺田大介（水産工学研究所）：

バイスペクトルの物理的な解釈について知見が あればご教授下さい。

\section{增山 聡：}

工学の分野に限らず、種々の研究分野においても バイスペクトル解析の適用例は非常に少ないといえ ます。船体動摇の時系列解析は物理現象と密接に関 係しており、物理的な知見が得やすい対象ではない かと考えられます。一連の研究で得られた知見は参 考文献(5)、(6)等の僅かなものしかありませんが、今 後研究を重㸚て行きたいと思います。 